\title{
Usability Evaluation of Instagram for Elderly Arab Users
}

\author{
Zinab Jarraf , Banan Farhoud, Ashjan Ali, Afraa Sayah, Dr. Kusum Yadav \\ College of Computer Science and Software Engineering \\ Department of Software Engineering \\ Hail University, $\mathrm{UOH}$ \\ Hail, Kingdom of Saudi Arabia \\ jarraf.zeno2019@gmail.com, shoojee2020@gmail.com, syrianbana95@gmail.com, \\ Afraax2016@gmail.co,kusumasyadav0@gmail.com
}

\begin{abstract}
Social networks are on a continuous developing and have become widely used throughout the world wide, which imperative the equal access by all users. Usability is a main quality requirement that ensures software success. Elderly users had difficulties in their usage as literature reported, but little empirical data on this topic does exist. Seeking universal usability is a main concern for professional networking; therefore the aim of this paper is to evaluate empirically Instagram Interface by elderly Arab. The finding of the study highlighted a set of computer usability challenges that need to be taken into account by designers and developers in order to improve the usability of the Instagram Desktop Interface for elderly Arab.
\end{abstract}

Key Words : Social Networks, Usability Evaluation, Instagram, Morae.

\section{Introduction}

Social networks are on a continuous developing and have turn out to be generally utilized all through the around the world. From sites got to on PCs to applications got to on cell phones, informal communities have pulled in a large number of clients in different classifications and on various stages. Furthermore, social network has proven its huge impact in providing social support for variant categories of life events and for different society groups [1]. In such cases social network had been positively correlated with social support in several medical cases such as survival after breast cancer diagnoses [2], post stroke [3] and for the elderly in prices as stated in [4] and [5]. Along these lines, the enhancing of this application ease of use is of foremost significance, particularly for elderly individuals that experience the ill effects of age-related issues. Ease of use is an essential plan highlight that adds to the ubiquity of an application [6] [7]. As indicated by ISO 9241, Part 11, ease of use is "The degree to which an item can be utilized by determined clients to accomplish determined objectives with viability, effectiveness, and fulfillment in a predefined setting of utilization." [8].

Presently, Instagram is one of the prevalent social network considering it is been used by millions of people of all ages for divers purposes around the world [13].

The aim of this paper is to evaluate the usability of Instagram Desktop interface 
focusing on the three attributes, which are effectiveness, efficiency and user satisfaction using PC. The evaluation method used the usability testing tool Morae [14] to gather data from the perspective of users and the SUS (System Usability Scale) questioner that is provided by the Morae will be used to capture the participant's subjective views of satisfaction. The SUS was developed by Brooky in 1996 [9] and from since till current time it had been used in various research papers such as [10], [11] and [12]. This empirical study focuses on elderly Arab users as it highlights a set of recommendations that have the potential to improve the usability of Instagram desktop interface on the website for them.

This paper is organized as follows: literate review II and in section III is the experiment. After that, section IV presents the evaluation results and discussion, then the conclusion and recommendations are presented in section $\mathrm{V}$.

\section{LITERATURE REVIEW}

Elderly users have different cognitive and physical capability than the younger crowed [15]. Research with empirical data on evaluation the various applications of the social media from this user perspective is limited. Mentioning a few such as Brian Wentz and Jonathan Lazar [15] in 2011 did a usability evaluation for Facebook on two different platforms. One was Facebook Desktop interface and the other was Mobile application with 15 blind people as participant in this study. The comparative result of their study concluded that the usability of Facebook on the Mobile is higher than on the Desktop. In 2014 K. C. Chinthakayala et al, did a comparative study on three famous social network website which are Facebook, Twitter and MySpace based on four criteria which are navigation, interactivity, source credibility and intelligence and proposed a ground and guidelines as for social network evaluation for evaluators [18]. Arfaa J. and Wang Y. in 2015 had proposed a redesign a social network interface design so the elderly can enjoy theses websites benefits which they tests its usability on 22 elderly and gain a positive reaction on the sites that adopted their interface [19]. In 2011 B. Wentz and J. Lazar led that Facebook versatile interface is more usable than Facebook Desktop interface; nonetheless, a few highlights are truant in the portable interface consequently it isn't lined up with the Desktop interface. The ramifications of this examination demonstrates to the subject of whether there is regularly an ease of use and usefulness contrast between the two interfaces for an application when one interface is recommended to be the "available" form.

\section{EXPERIMENT}

\subsection{Participants:}

The participants consist of two men who are both 50 years old and a one woman who is 47 years old. Both of the men are considered experts with using the computer, but the woman is a novice.

\subsection{Tasks Lists and Data Collection Instrument:}

Morae the usability engineering tool was chosen to conduct the evaluation from the user's viewpoint, which is representative of how the participants interact with the application to perform the following four tasks respectively: sign in, comment, Like and Sign out. Effectiveness will be determined by the accuracy of the participants' task accomplished successfully and the completion time that the participants spent on the tasks will be used to measure efficiency. After the participants finish performing the requested tasks they were requested to answer the SUS questionnaire to capture their subjective satisfaction. The evaluation was done using Instagram Desktop 
International Journal of Innovative Research in Applied Sciences and Engineering (IJIRASE) Volume 1, Issue 8, DOI: 10.29027/IJIRASE.v1.i8.2018.181-185, February 2018

Interface version 5.9 .5 on operating system Windows 7.

\section{Result AND Discussion}

Direct observation of the participants reveled that two of the participant completed all their tasks successfully, but the novice participant only completed the first task (Sign in) and fail to complete the remaining tasks as shown in table 1 . From the observation this user took $0.44 \mathrm{~min}$ for task 2 yet not completed because the like button was not clear for him and took 0.52 and 0.27 min trying to complete task 3 and 4 respectively. The time mean for each task by the users is illustrated in figure 1 and presented with the mean time of each task in table 2.

Table 1.Tasks Completion Ratio

\begin{tabular}{|l|c|c|c|c|}
\hline & $\begin{array}{l}\text { User } \\
\mathbf{1}\end{array}$ & $\begin{array}{l}\text { User } \\
\mathbf{2}\end{array}$ & $\begin{array}{l}\text { User } \\
\mathbf{3}\end{array}$ & Mean \\
\hline Sign in & 100 & 100 & 100 & 100 \\
\hline Comment & 100 & 100 & 0 & 66.66 \\
\hline Like & 100 & 100 & 0 & 66.66 \\
\hline Sign out & 100 & 100 & 0 & 66.66 \\
\hline
\end{tabular}

Figure 1.Tasks Completion Time by Each User

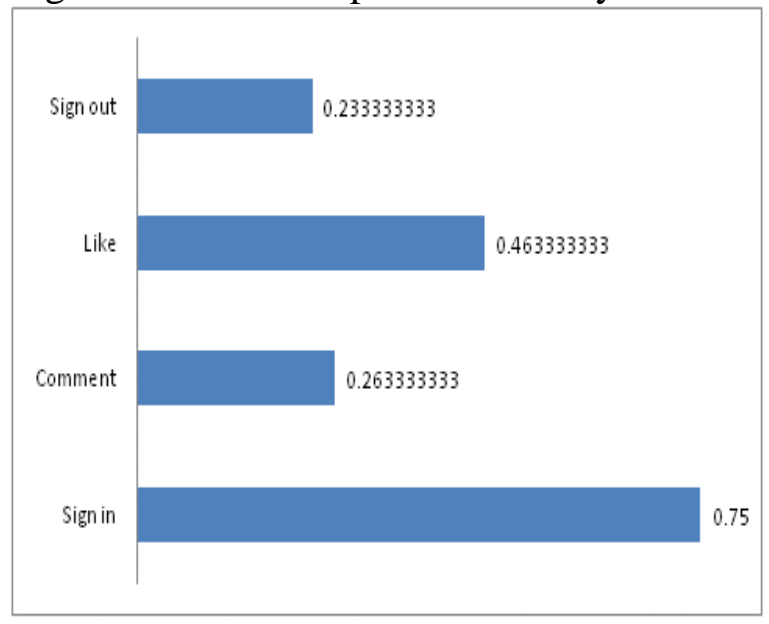

Table 2.Tasks Completion Time

\begin{tabular}{|l|c|c|c|c|}
\hline & User 1 & User 2 & User 3 & Mean \\
\hline Sign in & 0.66 & 0.45 & 1.14 & 0.75 \\
\hline Comment & 0.17 & 0.18 & 0.44 & 0.263 \\
\hline Like & 0.51 & 0.36 & 0.52 & 0.463 \\
\hline Sign out & 0.24 & 0.19 & 0.27 & 0.233 \\
\hline
\end{tabular}

Table 3 below demonstrates the result of the SUS scale which resulted in a score that is equal to 52.56 which is less than 68 that represent the average score in this scale indicating the existing of usability problems.

Table 3.System Usability Scale (SUS)

\begin{tabular}{|c|c|}
\hline User & SUS Score \\
\hline 1 & 47.7 \\
\hline 2 & 77.5 \\
\hline 3 & 32.5 \\
\hline Average & 52.5666667 \\
\hline
\end{tabular}

The outcomes assembled in the analysis demonstrate that the elderly clients had marginally more trouble in playing out a portion of the given undertakings. As saw amid the test and as revealed in the input, the members confronted impediments regarding ease of use of cell phone.

\section{Conclusion and Recommendation}

The usage of social network such as Instagram is a fundamental requirement in professional networking. In this paper an evaluation for Instagram Desktop interface was performed and, identify some usability challenges by elderly Arab, in lighting user satisfaction which is a main factor of usability 
International Journal of Innovative Research in Applied Sciences and Engineering (IJIRASE) Volume 1, Issue 8, DOI: 10.29027/IJIRASE.v1.i8.2018.181-185, February 2018

that guide every developing phase. Suggestions that emerge from the study are listed below:

1. Provide a small description (use hint) of how to use the icons efficiently or help center.

2. The like button must be defined for example write (like) keyword below the button.

3. Enable users to change icons and font size as most elderly face vision impairment.

4. Enable user to choose interface preference from layout and color as some users consider bright colors annoying.

Further investigation should be conducted to assists Instagram and various social network applications to achieve and promote their universal accessibility and usability.

\section{References}

[1] J. Martí, M. Bolíbar and C. Lozares, "Network cohesion and social support," Social Networks, vol. 48, pp. 192-201, 2017.

[2] C. H. Kroenke et al, "Social Networks, Social Support, and Survival After Breast Cancer Diagnosis," Journal of Clinical Oncology, vol. 24, (7), pp. 1105-1111, 2006.

[3] S. Northcott et al, "A systematic review of the impact of stroke on social support and social networks: associated factors and patterns of change," Clinical Rehabilitation, vol. 30, (8), pp. 811-831, 2016.

[4] S. Chung, H. Jeon and A. Song, "The Influence of Social Networks and Social Support on Health Among Older Koreans at High Risk of Depression," Care Management Journals : Journal of Case Management ; the Journal of Long Term Home Health Care, vol. 17, (2), pp. 70-80, 2016.

[5] S. Garay Villegas, Montes de Oca Zavala, Verónica and J. Guillén, "Social Support and
Social Networks Among the Elderly in Mexico," Journal of Population Ageing, vol. 7, (2), pp. 143-159, 2014.

[6] Gafni,R ."Usability Issues in MobileWireless Information Systems",2009.

[7] S. Abrahão, et al., "Proceedings of the International Workshop on the Interplay between Usability Evaluation and Software Development (I-USED 2008)," in CEUR Workshop Proceedings, ISTI-CNR, Pisa, Italy, 2008.

[8] ISO/IEC, "ISO 9241-11 Ergonomic requirements for office work with visual display terminals (VDT)s - Part 11 Guidance on usability," ISO/IEC 924111:1998(E), 1998.

[9] J. Brooke, (1996) »SUS: a "quick and dirty" usability scale «, in P. W. Jordan, B. Hiomas, B. A. Weerdmeester in A. L. McClelland. Usability Evaluation in Industry. London: Taylor and Francis.

[10] A. Bangor, P. T. Kortum and J. T. Miller, "An Empirical Evaluation of the System Usability Scale," International Journal of Human-Computer Interaction, vol. 24, (6), pp. 574-594, 2008.

[11] K. Orfanou, N. Tselios and C. Katsanos, "Perceived usability evaluation of learning management systems: Empirical evaluation of the System Usability Scale," International Review of Research in Open and Distance Learning, vol. 16, (2), 2015.

[12] I. Dianat, Z. Ghanbari and M. AsghariJafarabadi, "Psychometric properties of the persian language version of the system usability scale," Health Promotion Perspectives, vol. 4, (1), pp. 8289, 2014.

[13] G. Blank and C. Lutz, "Representativeness of Social Media in Great Britain: Investigating Facebook, LinkedIn, Twitter, Pinterest, Google+, and Instagram," American Behavioral Scientist, vol. 61, (7), pp. 741-756, 2017. 
[14] Anonymous "The joy of ageing.(Public health round-up)(World Health Organization campaign on celebrating the lives of older people via Instagram)," Bulletin of the World Health Organization, vol. 94, (1), pp. 4, 2016.

[14]"Usability Testing | Morae | TechSmith", TechSmith, 2018. [Online]. Available:

https://www.techsmith.com/morae.html.

[Accessed: 1- Feb- 2018].

[15] B. Wentz and J. Lazar, "Are separate interfaces inherently unequal?: An evaluation with blind users of the usability of two interfaces for a social networking platform," in 2011, . DOI: 10.1145/1940761.1940774.

[16] H. W. Wahl and C. Tesch-Römer, Aging, sensory loss, and social functioning, in: Communication, Technology, and Aging: Opportunities and Challenges for the Future, N. Charness, D. C. Parks and B. A. Sabel, eds., Springer, New York, 2001, pp. 108-126.

[17] T. A. Hart, B. S. Chaparro and C. G. Halcomb, "Evaluating websites for older adults: adherence to 'senior-friendly' guidelines and end-user performance," Behaviour \& Information Technology, vol. 27, (3), pp. 191-199, 2008.

[18] K. C. Chinthakayala et al, "A comparative study of three social networking websites," World Wide Web, vol. 17, (6), pp. 1233-1259, 2014.

[19] Arfaa J., Wang Y.. (2015) Usability Evaluation of a Social Networking Site Prototype for the Elderly. In: Zhou J., Salvendy G. (eds) Human Aspects of IT for the Aged Population. Design for Aging. ITAP 2015. Lecture Notes in Computer Science, vol 9193. Springer, Cham.

[20] B. Wentz and J. Lazar, "Are separate interfaces inherently unequal?: An evaluation with blind users of the usability of two interfaces for a social networking platform," in 2011, . DOI: 10.1145/1940761.1940774. 